\title{
Poesia em compromisso com o Amazonas
}

\author{
Poetry compromised with Amazonas
}

Ruane Maciel Kaminski Alves
UNIOESTE
ruanekaminski@gmail.com

Ximena Antonia Díaz Merino
UNIOESTE
xdmerino@ig.com.br

RESUMO: Amadeu Thiago de Mello, conhecido como Thiago de Mello, nasceu na cidade de Barreirinha na Amazônia, em 30 de março de 1926, à direita do rio Paraná do Ramos, braço mais comprido do Rio Amazonas. Partese das próprias palavras do autor, que discursa sobre literatura e resistência, o canto a serviço da liberdade, seu compromisso como intelectual e sua escrita para libertar os homens do silêncio e da apatia. O locus enunciativo dos versos poéticos e das entrevistas de Thiago de Mello revelam a estetização da floresta e do rio de sua terra natal. $\mathrm{O}$ autor define em encontros e entrevistas três utopias que regem a sua vida e marcam sua produção como poeta: a preservação ou salvação da floresta amazônica, a integração cultural da América Latina e a criação de uma sociedade humana mais solidária. Assim, para o autor, a poesia deve servir também à sociedade. Para refletir sobre a ideia de resistência na poesia de Thiago de Mello, separamos como corpus trechos de entrevistas e fragmentos do livro Amazonas, Pátria da Água (2005), que serão analisados a partir de estudos de Alfredo Bosi (2002), Leyla Perrone-Moisés (2005), Roberto Pontes (1999) e Silviano Santiago (2000).

Palavras-chave: Poesia comprometida. Resistência. Amazônia. Mitos.

ABSTRACT: Amadeu Thiago de Mello, known as Thiago de Mello, was born in Barreirinha on Amazon, march 30, 1926, the right side of the Paraná dos Ramos river, longer arm of the Amazon River. Starts from the words of the author, that speaks about literature and resistance, on the corner of the service of freedom, about his commitment as an intellectual and on your writing to liberate men from the silence and apathy. The locus of enunciation of Thiago de Mello's verses and enterviews reveal the aesthetics of the forest and of his

Revista Texto Poético | ISSN: 1808-5385 | Vol. 18 (10 sem-2015) - p. 89 
native river. The author defines, at meetings and interviews, three utopias that govern your life and mark their production as a poet: the preservation and salvation of the Amazon rainforest, the cultural integration of Latin America and the creation of a more harmonious human society. Thus, for the bard, poetry must also serve society. To reflect on the idea of resistance poetry Thiago de Mello, separated as corpus snippets of interviews and fragments of the book Amazon homeland Water (2005), which will be analyzed from studies of Alfredo Bosi (2002), Leyla Perrone-Moisés (2005), Roberto Pontes (1999) and Silviano Santiago (2000).

Keywords: Compromised poetry. Resistance. Amazon. Myths.

\section{Introdução}

Amadeu Thiago de Mello, conhecido como Thiago de Mello, nasceu na cidade de Barreirinha na Amazônia, em 30 de março de 1926, à direita do rio Paraná do Ramos, braço mais comprido do Rio Amazonas. Em entrevista ao programa Imagem da Palavra ${ }^{8}$, o poeta fala sobre sua trajetória artística e sua criação literária. Ao ser questionado sobre a sua vocação para a poesia, afirma que "[...] o poeta não se faz, o artista não se faz. O poeta nasce, eu nasci poeta" (THIAGO DE MELLO, 2012). Assim, relembra uma história de infância na qual, ao ver seu amigo morrer, escreveu um pequeno poema. Anos depois, contou a história a Manuel Bandeira que disse a Thiago que ali neste poema havia escrito um terceto com cada verso em sete sílabas, reforçando a ideia inicial do poeta amazonense de que o poeta não se faz, mas nasce desta forma.

Ganhador de dois Prêmios Jabuti pelos livros De uma vez por todas e Campos de Milagres, em 1997 e 2002, atualmente, o artista mora na sua cidade natal e revela que os estudos durante a sua

${ }^{8}$ Programa exibido no dia 27/12/2012 pela Rede Minas Tv em parceria com a Fundação TV Minas Cultural e Educativa FTVM, realização Rede Minas. 
juventude na Faculdade de Medicina no Rio de Janeiro, a qual cursou até o quarto ano, são empregados ainda hoje para auxiliar a comunidade em que vive, que sofre com a falta de médicos. Foi durante o curso de graduação com 16 e 17 anos que, a partir dos poemas de Manuel Bandeira e Carlos Drummond de Andrade, descobriu a beleza da poesia e descobriu-se poeta também. Assim, aos 25 anos, Thiago de Mello lançou seu primeiro livro, Silêncio e Palavra (1951).

Para falar da produção literária do escritor amazonense Thiago de Mello, parte-se das próprias palavras do autor, que ao refletir sobre sua produção discursiva, sobre literatura e resistência, canto a serviço da liberdade, do seu compromisso como intelectual e de sua escrita para libertar os homens do silêncio e da apatia. Para trabalhar esta ideia de resistência na poesia de Thiago de Mello, separamos como corpus, trechos de entrevistas e fragmentos dos poemas do autor. O poeta é um grande representante das artes no país, respeitado e reconhecido por sua produção, principalmente como um ícone regional. As entrevistas selecionadas datam dos anos de 1999, 2009, 2011 e 2012.

As entrevistas são importantes para entender o processo criativo porque trazem à tona uma concepção de mundo e do tempo que o autor ocupa. Elas ganham um status de escrita crítica, na perspectiva de Leyla Perrone-Moisés, em Texto, crítica, escritura (2005):

$\mathrm{Na}$ escritura, o sujeito individual cede seu lugar a um sujeito de enunciação que se constitui e se desconstitui incessantemente, em seu próprio trabalho, colocando em situação de crise (em situação crítica) o sujeito e todo o contexto em que irrompe seu texto (PERRONE-MOISÉS, 2005, p. 27). 
Percebem-se, durante a escrita de Thiago de Mello, suas preocupações, histórias de vida e expectativas para um futuro, construindo e desconstruindo o seu próprio ser e suas ideias. A exemplo do poema A lição do rio, no qual o eu-lírico canta: "Como um rio, que nasce de outros, saber seguir junto com outros sendo e noutros se prolongando e construir o encontro com as águas grandes do oceano sem fim. Mudar em movimento, mas sem deixar de ser o mesmo ser que muda. Como o rio" (THIAGO DE MELLO, 2005). Nesta passagem, percebe a concepção do próprio autor sobre a constituição do $\mathrm{Eu}$ através do processo de alteridade, além da mutabilidade e fluidez das identidades.

Na entrevista ao jornal eletrônico Dom Total (2011), Thiago revela que o seu grande interesse pela floresta, além da sua origem e da sua morada atual, o que o levou a retornar do exílio e fixar-se na floresta, foi o conhecimento sobre preservação e devastação adquirido durante sua estada na Europa e a sua vontade de aprender mais com a floresta e com o povo que vive nela. Foi muito questionado sobre sua decisão, mas ele sempre afirma:

Não vou lá para ensinar. Quero e preciso ir é para aprender com a floresta e com o povo que vive nela. Que é parte essencial da floresta. Com as águas, os verdes, as estrelas, o chão onde nasci. Não quero aprender só com os livros, as noticias dos jornais e dos satélites (THIAGO DE MELLO, 2009b).

Thiago de Mello a partir das entrevistas confessa o seu interesse pela floresta e pelo rio, o que se concretiza nas suas poesias, que, como será demonstrado posteriormente, possui um caráter de resistência e comprometimento. $\mathrm{O}$ seu desejo de conhecer mais sobre a floresta e sobre as populações que dependem diretamente 
dela é constantemente reforçado nas entrevistas e nos seus livros que buscam também um "ensinamento" aos homens sobre este espaço tão fundamental em nossas vidas e também para aprender com a floresta questões sobre respeito e amor ao próximo.

\section{Um poeta utópico e comprometido}

Os temas da produção literária de Thiago de Mello não fogem da estetização do locus enunciativo: a floresta e o rio. $\mathrm{O}$ autor na entrevista ao programa Imagem da Palavra (2012) define as três utopias que regem a sua vida e sua poesia: a preservação ou salvação da floresta, a integração cultural da América Latina e a criação de uma sociedade humana mais solidária:

Eu dedico a minha vida a três causas: primeiro, era a preservação, mas em virtude do aquecimento da terra, eu chamo da salvação da vida da floresta amazônica, que é o maior manancial de riqueza e de vida do planeta Terra. A segunda é a integração cultural da nossa América. A verdadeira América somos nós. Colombo descobriu a América foi aqui no continente americano. América por causa do Américo Vespúcio. Ai os Estados Unidos decidiram que são América também. São América coisa nenhuma. Americanos somos nós. Integração cultural da nossa América porque nós não nos conhecemos. E como eu acho que não haverá integração política, integração econômica. Sem uma verdadeira integração cultural do povo, que o povo se conheça não só através do futebol [...] através da literatura, da arte, da vida de cada povo [...]. E a terceira: O leitor que já perdeu a esperança, que está me ouvindo e está pensando já, que já perdeu a esperança, já perdeu até a juventude, só pensa realmente em ficar rico. Eu me dedico a fazer a minha parte, na construção, porque é possível, sim, a construção de uma sociedade humana e 
solidária. E eu peço a cada um que faça a sua parte (THIAGO DE MELLO, 2012).

As utopias que o guiam na forma de viver a vida, e que também são levadas pelo mundo através das suas mensagens em palestras e eventos, regem a sua produção artística intensamente, pois, para o poeta, a poesia possui um papel conscientizador, integrador e também o poder de amor. O entrevistador José Castello, na entrevista Thiago de Mello: uma vida é um campo de milagres ${ }^{9}$ (1999), comenta que a produção do poeta amazonense está além dessa redução ideológica, pois ele se mantém "[...] apegado aos temas primitivos e lentos do Baixo Amazonas, aos versos soltos e derramados e, apesar de ateu, a uma visão da poesia como milagre" (CASTELLO, 1999).

A forte presença, em seus poemas, dos elementos naturais da Amazônia e da busca constante da preservação da floresta e do bemestar dos homens se revela nos títulos de suas obras, Manaus - amor e memória (1984); Amazônia, a menina dos olhos do mundo (1992); Amazonas, pátria da água (2005); ABC da Floresta Amazônica (2008), entre outros. No livro, Amazonas, pátria da água (2005), Thiago de Mello elabora um manifesto em defesa da Natureza e da Amazônia. Assim, nos apresenta a vida da floresta e sua história com os riscos e perigos que assombram esta região, como se percebe nos títulos dos poemas e na temática, sempre sobre a floresta, seus animais, seus mitos, etc.

Me fiz gente no meio de madeira, as achas encharcadas, lenha verde,

${ }^{9}$ Entrevista concedida a José Castello para o Jornal O Estado de São Paulo, 08/05/1999.

Revista Texto Poético | ISSN: 1808-5385 | Vol. 18 (10 sem-2015) - p. 94 
minha mãe reclamava da fumaça.

Na verdade abri os olhos vendo madeira, o belo madeirame de itaúba

da casa do meu avô no Bom Socorro,

onde meu pai nasceu

e onde eu também nasci.

(THIAGO DE MELLO, 2005).

Sobre a sua poesia, Thiago de Mello é rotulado como um "poeta engajado", o que confunde a sua poesia combativa e humanista com ideologia e sectarismo. Em resposta ao questionamento sobre este equívoco da crítica, na entrevista para Dom Total (2011), o poeta responde que "a inquietação social faz parte da história da poesia desde o começo da humanidade, a poesia nasce do povo, por isso digo 'aqui está a minha vida pronta para ser usada"” (THIAGO DE MELLO, 2011). Assim, para o poeta, a poesia deve servir também à sociedade e, como a sua produção foi muito combativa durante o período da ditadura, então se tem a ideia de autor perigoso, segundo o próprio autor sobre sua trajetória. A exemplo do poema Canto do meu canto, que explora a criação da poesia como de responsabilidade humana e social e não apenas estética, mas histórica.

\footnotetext{
[...] Escrevi no chão do outrora

e agora me reconheço:

pelas minhas cercanias

passeio, mal me frequento.

Mas pelo pouco que sei

de mim, de tudo que fiz,

posso me ter por contente,

cheguei a servir à vida,

me valendo das palavras.
} 
Mas dito seja, de uma vez por todas,

que nada faço por literatura,

que nada tenho a ver com a história,

mesmo concisa, das letras brasileiras.

Meu compromisso é com a vida do homem,

a quem trato de servir

com a arte do poema. Sei que a poesia

é um dom, nasceu comigo.

Assim trabalho o meu verso,

com buril, plaina, sintaxe.

Não basta ser bom de oficio.

Sem amor não se faz arte. [...]

(THIAGO DE MELLO, XX).

Thiago também comenta sobre a sua produção e afirma que a poesia é sentimento, mas também é inteligência, pois o coração é igualmente inteligente. Reafirma, em entrevista ao Programa 3 a 1 (2009a), que "a poesia tem uma finalidade estética, o compromisso do artista com a arte. Mas a poesia tem que ter uma utilidade ética, tem que servir à vida. Em que você lê o poema e mexe contigo" (THIAGO DE MELLO, 2009a).

O desejo de servir ao povo e o entendimento do dever do poeta de "[...] ser melhor e servir mais à vida de todos." (THIAGO DE MELLO, 2011), conforme justifica Thiago de Mello, intensificaram-se com o período do exílio, no qual ele perdeu a sua vaidade, seu orgulho e ficou mais humilde para entender que deveria transmitir amor às pessoas. Durante o período da ditadura, antes do exílio, Thiago exercia a função de assessor cultural na Embaixada do Brasil no Chile, em 1961, período que conheceu seu grande amigo, Pablo Neruda. A sua amizade com Neruda, de acordo com Maria de Souza e Cássia do Nascimento, no artigo "Pablo Neruda e Thiago de Mello: amizade e poesia insubmissa em tempos inglórios" 
(2014), contribuiu para a constituição da denominada "poesia insubmissa" $"$.

$\mathrm{O}$ exílio, de acordo com o autor, foi consequência de seu protesto contra a ditadura militar de 64 e por tratar em seus poemas de temas como a liberdade e a degradação dos homens, ou seja, a tortura. Em entrevista ao programa Imagem da Palavra (2012), Thiago de Mello reflete que a sua escrita sobre o aviltamento humano da tortura é considerada um tema político, mas, para ele, trata-se de uma questão humana e de defesa da dignidade também. A análise do poeta e de sua poesia insubmissa, segundo Souza e Nascimento (2014), direciona o olhar para além da produção artística, mas acima de tudo para entendê-lo como "[...] cidadão engajado e compromisso com a liberdade" (SOUZA; NASCIMENTO, 2014, p. 2).

De acordo com as autoras citadas acima, Neruda e Thiago conciliavam suas carreiras literárias com a luta social e humana, sempre atentos para denunciar os desmandos políticos e abusos contra a natureza. Como diz no poema "A vida verdadeira", no livro Amazônia, pátria da água (2005), Thiago de Mello não tem um caminho novo a apresentar, mas "o que tenho de novo / é o jeito de caminhar" (THIAGO DE MELLO, 1999). Assim, Thiago reconhece que ele continua o mesmo, mas mudou a sua forma de caminhar, de pensar e produzir a sua poesia, "[...] a qual ele próprio chama de poesia comprometida, e à qual chamamos de poesia insubmissa" (SOUZA; NASCIMENTO, 2014, p. 7). Esse movimento da poesia comprometida foi intenso no período ditatorial e ainda se mantém

${ }^{10}$ A poesia insubmissa, conceito elaborado por Roberto Pontes, é a produção relacionada com o "[...] enfrentamento e livramento da opressão detectada pelo poeta e acolhimento de sua poesia pela coletividade sedenta de verdade" (PONTES, 1999, p. 30).

Revista Texto Poético | ISSN: 1808-5385 | Vol. 18 (10 sem-2015) - p. 97 
na produção artística do poeta, que revela traços de denúncia e busca ser um guia para os homens:
[...] Não tenho o sol escondido
no meu bolso de palavras.
Sou simplesmente um homem
para quem já a primeira
e desolada pessoa
do singular - foi deixando,
devagar, sofridamente
de ser, para transformar-se
- muito mais sofridamente-
na primeira e profunda pessoa
do plural.
Não importa que doa: é tempo
de avançar de mão dada
com quem vai no mesmo rumo,
mesmo que longe ainda esteja
de aprender a conjugar
$o$ verbo amar. [...]
(THIAGO DE MELLO)

A produção de Thiago de Mello, portanto, contém a noção de literatura e resistência, ao modo explicado por Alfredo Bosi (2002). Para tratar do conceito de resistência, Bosi revisita a dialética das distinções de Benedetto Croce, segundo a qual, ética e estética seriam de campos diferentes do conhecimento, mas, com a possibilidade de translação de sentido entre as duas esferas. Para que sejam interconectadas, é necessário que o autor explore os valores da vida em sociedade - parte do tecido vivo de qualquer cultura. Interferindo diretamente no trato social, os valores estariam no fim da ação - como objetivo dela - e em seu princípio - como motivação. Esta interação entre os campos estético e ético garante 
ao autor a possibilidade de uma escrita de resistência, uma vez que resgata discursos da sociedade em sua poesia.

\title{
Um poeta vestido de branco
}

Como aponta Antonio Candido em Literatura e Sociedade (2006), os elementos externos importam na obra, não apenas como causa ou significado, mas na constituição de sua estrutura, o que os tornam internos. A poesia de Thiago de Mello, portanto, utiliza os elementos sociais e culturais em um nível explicativo, pois entende que a sua obra está inserida em um contexto histórico e cultural e possui um dever social, como o poema Os estatutos do homem (Ato institucional permanente) (1977), formulado no esquema de estatutos de lei, "cria" novos direitos fundamentais aos homens:

\author{
[...] Artigo IV \\ Fica decretado que o homem \\ não precisará nunca mais \\ duvidar do homem.
}

Que o homem confiará no homem

como a palmeira confia no vento, como o vento confia no ar, como o ar confia no campo azul do céu.

Parágrafo único:

O homem, confiará no homem como um menino confia em outro menino. [...] (THIAGO DE MELLO, 1977).

A degradação humana que se revela na violência e na ditadura, assim como a devastação da floresta, a falta de amor e solidariedade entre as pessoas como também o desconhecimento da cultura dos nossos países vizinhos são elementos que funcionam não apenas 
como ilustração ao texto, mas se tornam essenciais para a compreensão da sua produção.

No livro Amazonas, Pátria da Água (2005), Thiago denuncia a destruição da floresta e a extração de recursos naturais de forma discriminatória,

A Floresta Amazônica, fragmentada em toros, espremida na superficie dos compensados, hoje é levada para todos os lugares do mundo. Sucede que muitas vezes ela é simplesmente devastada, destruída pelo fogo, consumida pela ganância, que não pode perder tempo, das grandes empresas pecuárias (THIAGO DE MELLO, 2005, p. 41).

Thiago de Mello, durante a entrevista ao Programa $3 a 1^{11}$, para a TV Brasil, revela que ao viajar, seja no interior do Brasil ou no exterior, ele sempre clama: "Faça tua parte pela preservação da floresta" (THIAGO DE MELLO, 2009a). O autor ainda explica que, "Quando eu digo a floresta e preservação da floresta, eu tô dizendo da elevação da qualidade de vida do homem que vive nela e vive dela [...]. Porque serve ao homem que vive nela e serve ao resto da humanidade" (THIAGO DE MELLO, 2009a).

Em seus poemas e contos, Thiago de Mello revela ter consciência de que a floresta e o rio são parte da vida do homem,

A extração da madeira da floresta, iniciada desde o instante em que o primeiro índio derrubou a primeira árvore para fazer a sua canoa e construir a sua maloca,

${ }^{11}$ Entrevista exibida pela TV Brasil no dia 23/11/2009 e postada no Youtube no dia 23/02/2010, concedida ao apresentador Luiz Carlos Azedo e pelos debatedores Tereza Cruvinel, presidente da TV Brasil, e José Carlos Vieira, Editor de Cultura do jornal Correio Braziliense.

Revista Texto Poético | ISSN: 1808-5385 | Vol. 18 (10 sem-2015) - p. 100 
nunca mais cessou. E tomara, vamos com calma, que não cesse nunca. Este necessário uso da floresta faz parte do processo cultural, resultante do convivio, da interação entre homem e natureza (THIAGO DE MELLO, 2005, $p$. 40).

Para Mello, essa convivência e também dependência do homem à floresta está carregada de um dever de preservação, ou melhor, de salvação, dado que a floresta já se encontra em um estado de decadência e de exploração sem consciência. No Programa Imagem da Palavra (2012), Thiago de Mello expressa o dever do poeta e do literato de levar amor às pessoas e define que ser poeta é "atender" à humanidade. O meio da floresta e o convívio dos homens, portanto, além de fazer parte da vida e do cotidiano do autor, também é a sua maior preocupação com o futuro.

Thiago de Mello veste-se de branco pela paz e, nesta luta por uma sociedade melhor, regida pelas três utopias, o poeta desenvolve em seus ensaios as suas dores por uma floresta machucada e explorada e por ver o povo ribeirinho também explorado. No livro Amazonas, pátria da água (2005), está explícita a vontade do autor de denunciar estes atentados à natureza e ao homem, um canto em favor da liberdade e da redenção destes, para que eles aprendam novamente a simplicidade e o amor ao próximo:

Filho da floresta, água e madeira, voltei para ajudar na construção do morada futura. Raça de âmagos, um dia chegarão as proas claras para os verdes livrar da servidão (THIAGO DE MELLO, 2005) ${ }^{12}$.

${ }^{12}$ Poema "Filho da floresta, água e madeira".

Revista Texto Poético | ISSN: 1808-5385 | Vol. 18 (1o sem-2015) - p. 101 
Voltada para esse locus enunciativo que é a Amazônia, a sua poesia ganha dimensões universais pelas imagens da água e dos mitos. Pois os mitos relacionados, como do boto e do curupira, alcançam o universal já que a imagem da água e o mito não atingem apenas a Amazônia. Como o próprio poeta afirma em A fundação da pátria da água, a Amazônia é a

\begin{abstract}
[...] planície que ocupa a vigésima parte da superficie deste lugar chamado Terra, onde moramos. Verde universo equatorial que abrange nove países da América Latina e ocupa quase a metade do chão brasileiro. Aqui está a maior reserva de água doce, ramificada em milhares de caminhos de água, mágico labirinto que de si mesmo se recria incessante, atravessando milhões de quilometros quadrados de território verde (THIAGO DE MELLO, 2005, $p$. 15).
\end{abstract}

Em entrevista ao Movimento Humanos Direitos (2009) ${ }^{13}$, Thiago revela que sente uma grande tristeza quando visita alguma aldeia e a sua população já não se lembra de suas lendas. As lendas, para o poeta, representam mais do que simples histórias, pois elas sempre contêm um ensinamento, como $O$ caso da Neca, lenda sobre a mentira e a maldade que contavam às crianças; como também a história do boto, que alerta para os perigos da água provocados “[...] pelas doenças adquiridas na convivência constante do homem com a água. A água poluída [...] A água contaminada [...] Água que o homem suja [...] Mas há algumas doenças oriundas da própria água" (THIAGO DE MELLO, 2005).

${ }^{13}$ Entrevista concedida ao Movimento Humanos Direitos (MHuD) na Revista Direitos Humanos, de 03 de junho de 2009.

Revista Texto Poético | ISSN: 1808-5385 | Vol. 18 (10 sem-2015) - p. 102 
Esse processo de "aculturação" dos índios significa a perda de identidade dos mesmos, que possuem o direito de serem índios aonde forem e com o mínimo de dignidade. No monólogo do índio apresentado no capítulo Solilóquio do índio, destaca-se a imagem desse índio perdido dentro de uma cultura que não lhe pertence:

\author{
Já deslembrado da glória \\ radiosa de conviver, \\ já perdido o parentesco \\ com a água, o fogo, as estrelas, \\ Já sem crença, já sem chão, \\ Oco e opaco me converto \\ Em depósito de restos \\ Impuros do ser alheio. \\ Residuo de mim, a brasa \\ do que já fui me reclama, \\ Como a luz que me conhece \\ de uma estrela agonizante \\ dentro do ser que perdi. \\ (THIAGO DE MELLO, 2005).
}

O processo de colonização, para o poeta, portanto, causou a devastação não apenas da floresta, mas dessa imensidade que era a população indígena antes da chegada do homem branco. No livro Amazonas, pátria da água, Thiago revela que os pequenos resíduos tribais no Brasil apenas desejam "[...] o direto de ser o que são" (THIAGO DE MELLO, 2005, p. 72). Como reforça na entrevista, "Quase todos feridos fundamente em sua essencial condição de índios. Uns poucos resistem, nas lonjuras da selva, evitando o contato com os chamados agentes da civilização" (THIAGO DE MELLO, 2009b).

Neste desejo utópico de constituição de uma sociedade mais humana, pode-se visualizar o conceito que Silviano Santiago apresenta aos escritores latino-americanos: "Falar, escrever,

Revista Texto Poético | ISSN: 1808-5385 | Vol. 18 (1o sem-2015) - p. 103 
significa: falar contra, escrever contra" (SANTIAGO, 2000, p. 17). $\mathrm{O}$ bom texto não é o texto que incita a preguiça, mas aquele que

[...] deve descondicionar o leitor, tornar impossivel sua vida no interior da sociedade burguesa e de consumo. A leitura fácil dá razão às forças neocolonialistas que insistem no fato de que o país se encontra na situação de colônia pela preguiça de seus habitantes. O escritor latinoamericano nos ensina que é preciso liberar a imagem de uma América Latina sorridente e feliz, o carnaval e a fiesta, colônia de férias para turismo cultural (SANTIAGO, 2000, p. 26).

No livro Amazonas, pátria da água (2005), esse desejo de denunciar e alarmar a devastação da floresta e também do ser humano, em geral, está relacionado à ideia de que o autor tem um dever com a sua sociedade, como é expresso na entrevista a Lêda Rivas $^{14}$, no Jornal da Poesia:

Acho que a poesia da América Latina, hoje, é uma poesia essencialmente ligada à vida do homem latino-americano. Uma poesia que serve à vida. A poesia, evidentemente, é uma arte, mas esta arte deve servir à vida. Ou seja, além de ter uma finalidade estética, deve ter uma utilidade ética. Ela não deve servir apenas à beleza, ela deve servir ao bem. Ao bem da vida. (THIAGO DE MELLO, sd)

A busca de servir à vida e ao bem impulsionou Thiago de Mello a escrever em Amazonas, pátria da água (2005) um clamor à humanidade para pensar em um futuro mais digno e humano que também respeite a natureza:

${ }^{14}$ Editora do Viver, caderno de cultura do Diário de Pernambuco.

Revista Texto Poético | ISSN: 1808-5385 | Vol. 18 (1o sem-2015) - p. 104 
[...] é o futuro da própria Humanidade que está ameaçado, os olhos amanhecem cada dia mais abertos para o perigo de uma catástrofe nuclear. Mas sucede que não acredito no triunfo definitivo da loucura e da insensatez. Não consigo perder a esperança no futuro da convivência humana. (THIAGO DE MELLO, 2005, p. 79).

Thiago de Mello frisa em sua entrevista ao MHud que podemos sim mudar o povo brasileiro, mesmo perante a frágil situação social do Brasil, assim,

Quem sabe vai ser preciso que se dê uma grande sacudida. Quem vai dar eu acho que vai ser a Terra. Eu? Não. Os cientistas do mundo inteiro, que não brincam com as palavras. Advertem que estamos no século do "grande desastre da humanidade”. Grande parte dela vai perecer. [...] Os sobreviventes vão construir não o admirável mundo novo do Aldous Huxley, mas um novo modo humano de viver. Um modelo de vida diferente. Dentro de outro sistema, que inventarão. Uma sociedade humana solidária (THIAGO DE MELLO, 2009b).

A poesia de Thiago de Mello, portanto, cumpre o seu dever com a humanidade de não se acomodar ou acostumar com os problemas sociais, ambientais ou humanos que se escondem nas relações diárias. $\mathrm{O}$ poeta lança questões sobre o passado e presente de forma a provocar no leitor uma análise sobre o seu futuro e sobre o futuro de toda a humanidade. Vestido sempre de branco, Thiago de Mello preferiu a utopia à descrença na humanidade ou ao apocalipse. Lutando pela paz, sempre comprometido, mas não reduzido às causas políticas, Thiago revela nas suas entrevistas que “[...] a poesia não dá lucro" (2009a), mas nem por isso se arrepende 
das suas escolhas, pois a escrita é o seu dom, dom de servir e enviar amor e luz à vida de todos.

\section{Referências}

BOSI, Alfredo. Literatura e resistência. São Paulo: Companhia das Letras, 2002.

CANDIDO, Antonio. Literatura e Sociedade. Rio de Janeiro: Ouro sobre azul, 2006.

FURTADO, Pollyanna; MELLO, Thiago de. ABC da Floresta Amazônica.

Fortaleza: Conhecimento, 2008.

MELLO, Thiago de. Manaus - Amor e Memória. São Paulo: Martin Fontes, 1984.

MELLO, Thiago de. Amazônia, a menina dos olhos do mundo. São Paulo:

Saraiva, 1992.

MELLO, Thiago de. Amazonas: pátria da água. Rio de Janeiro: Bertrand Brasil, 2005.

MELLO, Thiago de. A vida verdadeira. In: Faz escuro mas eu canto. Rio de Janeiro: Bertrand Brasil, 1999.

MELLO, Thiago de. Thiago de Mello: depoimento [23 de novembro de 2009a]. Brasília: Programa 3 a1. Entrevista concedida a Luiz Carlos Azedo, Tereza Cruvinel e José Carlos Vieira.

MELLO, Thiago de. Thiago de Mello: depoimento [28 de dezembro de 2012]. Minas Gerais: Imagem da palavra. Entrevista concedida a Guga Barros da Fundação TV Minas Cultural e Educativa.

MELLO, Thiago de. Thiago de Mello: depoimento [sd]. Pernambuco: Jornal da Poesia. Entrevista concedida a Lêda Rivas.

MELLO, Thiago de. Thiago de Mello é entrevistado pelo MHuD: depoimento [03 de junho de 2009b]. Rio de Janeiro: Revista Direitos Humanos. Entrevista concedida ao Movimento Humanos Direitos. 
MELLO, Thiago de. Thiago de Mello: o clamor de um poeta: depoimento [08 de julho de 2011]. Belo Horizonte: Revista Dom Total. Entrevista concedida a Marco Lacerda.

MELLO, Thiago de. Thiago de Mello, vida é um campo de milagres: depoimento [08 de maio de 1999]. São Paulo: O estado de São Paulo. Entrevista concedida a José Castello.

PERRONE-MOISÉS, Leyla. Texto, crítica, escritura. São Paulo: Martins Fontes, 2005.

PONTES, Roberto. Poesia insubmissa afrobrasilusa: estudo da obra de José Gomes Ferreira, Carlos Drummond de Andrade e Agostinho Neto. Rio de Janeiro: Oficina do Autor, 1999.

SANTIAGO, Silviano. Uma literatura nos trópicos. Rio de Janeiro: Rocco: 2000.

SOUZA, Maria L. S. de; NASCIMENTO, Cássia M. B. do. PABLO NERUDA E THIAGO DE MELLO: poesia insubmissa em tempos inglórios. In: VI JORNADA DE RESIDUALIDADE LITERÁRIA E CULTURAL. 2014, Ceará, (Anais), Ceará, Edições UFC, 2014, p. 01-10. 